This volume is special in many ways. Firstly, it comes after the successful LIASA conference held in the "Mother City", Cape Town, in October 2008. Secondly, we are bidding a special farewell to our long serving Editor-in-Chief, Professor Dennis Ocholla and welcoming aboard Professor Patrick Ngulube. We wish to pay tribute to Professor Ocholla for the professional services that he tirelessly rendered to the Journal over the years. This issue contains a variety of interesting articles, most of which were inherited from Prof Ocholla.

The first article, by Stephen Mutula, looks at local content development projects in Africa. The article unpacks the concept of 'content' and its derivative 'local content'. It further elucidates the confusing nexus between 'local content' and indigenous knowledge, and asserts that IK is in fact a special form of local content. The benefits of local content to the economy are discussed, as are the challenges. The paper submits that contrary to widely held perceptions, Africa has made good progress towards developing and managing its local content.

The next article, by Peter Lor on digital libraries and archiving knowledge, posits that modern digital technologies offer new possibilities of achieving universality, but also present big challenges. The article raises some critical questions about the concepts of "digital libraries" and "archiving knowledge". It uses a basic life-cycle approach to digital libraries and considers digital library functions within the cycle of the creation, dissemination, disposal and use of born-digital and digitised content. Different types of digital libraries are identified and challenges in selection, acquisition, organisation, preservation, resource discovery and access are discussed.

LIS qualifications are fundamental to shaping the future of librarianship in Africa. According to Jaya Raju, it is important for countries in Africa to blaze their own unique paths in terms of adopting LIS qualification models that would be realistic and relevant to the local African context and, importantly, add value to their library and information services which have a crucial role to play in growth and development. Based on the preliminary findings of research conducted in South Africa, the article concludes that while there are significant aspects of western developed qualification models that continue to be useful in developing contexts, LIS qualification models in these contexts do not necessarily have to travel the same route as in the West. The development of such qualification models should be guided by African realities. Finally, the article recommends the need to draw lessons from work place practices in other disciplines and from innovative work place behaviour within the LIS discipline.

Wole Michael Olatokun investigates the use of the Internet among secondary school students in Ibadan, a Nigerian municipality. The findings reveal that the majority of the respondents used the Internet mainly for leisure rather than for educational purposes. The greatest barrier to the full exploitation of the Internet was inadequate access. On another note, Christine Stilwell maps the fit between the library and information services available and the national transformation agenda in South Africa. The article reviews information policy and describes information sources, systems and services in South Africa as part of the wider national information system.

Patrick Ngulube and Elizabeth Conceição Garçia Thompson argue that the Web has significantly changed the milieu of research and study. The informetrics study that they conducted at the University of Natal in South Africa revealed that the use of the Web by students was rather limited. The use of this medium was disparate, with a few bibliographies accounting for much of the growth of Web resources. The study reveals greater support for this medium from the masters' programme's supervisors than was evidenced from a citation analysis of the bibliographies of theses.

Web users are becoming more critical of the web sites they use. In that light, Susan Mvungi, Karin de Jager and Peter Underwood evaluate the information architecture of the academic library web site at the University of Cape Town with more of a focus on the usability testing of the University web site. They found that the library had a generally usable web site. However, the site exhibited a few problems in terms of the terminology used, the navigation design, and issues relating to identifying specific information. This study presents recommendations to handle the aforementioned problems.

The last research article in this issue is by Jan Maluleka and Omwoyo Bosire Onyancha. They used bibliometric techniques to examine the frequency and pattern of referencing in articles published in South African Journal of Libraries and Information Science (SAJLIS) from 1996 to 2007. They found that SAJLIS has maintained a regular production of publications apart from the year 1999 when the journal was not published. On average, SAJLIS published I 5 articles per year between 1996 and 2007 . Journal articles were the most commonly consulted by SAJLIS authors, followed by books, then Internet-only sources and conference proceedings. The highest number of references recorded in a single article was IOI, while the lowest number of references was four. A general contribution by Lydmila Ocholla and Dennis Ocholla on the Fifteenth Jubilee International Conference (otherwise known as "Crimea 2008") concludes this issue.

\title{
Enjoy the read
}

Prof Patrick Ngulube

Editor-in Chief 